\title{
La Culpabilidad en la Responsabilidad por DaÑo Ambiental y su Relación con el Sistema de EVAluaCión de IMPACTO AMBIENTAL*
}

[Guilt in liability for environmental damages and its connection with the Chilean environmental impact assessment system]

\section{Jorge A. Femenías S.**}

\section{RESUMEN}

El presente artículo busca identificar cómo afecta en la determinación de la culpabilidad del causante del daño ambiental, la circunstancia de que su actividad deba someterse al Sistema de Evaluación de Impacto Ambiental (SEIA).

\section{Palabras Clave}

Responsabilidad por daño ambiental - Daños ambientales - Culpa - Dolo.

\section{ABSTRACT}

This article seeks to identify the impact, in the determination of the culpability of the agent who causes environmental damage, of the circumstance that its project must be submitted to the Environmental Impact Assessment System (SEIA).

\section{KeYwORDS}

Liability for environmental damageenvironmental damage - Guilt - Fraud.

RECIBIDO el 19 de diciembre de 2016 y ACEPTADO el 26 de mayo de 2017

* Algunas de las reflexiones expuestas en este trabajo forman parte de la Tesis para optar al Grado de Doctor en Derecho del suscrito, la que ha sido individualizada debidamente en la bibliografía.

** Doctor en Derecho por la Universidad de Valladolid (España) y Doctor en Derecho por la Pontificia Universidad Católica de Chile. Coordinador de Investigación del Programa Derecho y Medio Ambiente de la Facultad de Derecho de la Pontificia Universidad Católica de Chile. Abogado Asociado Senior del grupo de Medio Ambiente y Recursos Naturales en CorreaGubbins. Correo electrónico: jafemeni@uc.cl. 


\section{DAÑOS AMBIENTALES OCASIONADOS POR ACTIVIDADES QUE SE ENCUENTRAN OBLIGADAS A INGRESAR AL SISTEMA DE EVALUACIÓN DE IMPACTO AMBIENTAL}

El artículo 10 de la Ley de Bases Generales del Medio Ambiente (LBGMA) dispone que los proyectos o actividades que enumera y que sean susceptibles de causar impacto ambiental en cualquiera de sus fases, deberán someterse al Sistema de Evaluación de Impacto Ambiental (SEIA) ${ }^{1}$.

En consecuencia, existe por parte de los titulares de dichos proyectos o actividades, una obligación legal de no ejecutarlos o modificarlos sin la obtención previa de una autorización administrativa, pronunciada luego de concluido un proceso de evaluación de los impactos ambientales que pueda ocasionar dicho proyecto o actividad ${ }^{2}$.

A partir de dicha disposición, interesa preguntarse qué ocurre con aquellos proyectos o actividades que, encontrándose obligados a ser ingresadas al SEIA, no lo hicieron; o bien, que, habiéndose ingresado, han llevado a cabo acciones que ocasionaron efectos ambientales significativamente adversos o, derechamente, daños ecológicos puros.

1. Daños ambientales ocasionados por actividades que encontrándose obligadas a ser ingresadas al SEIA no lo hicieron

La primera hipótesis que se puede presentar dice relación con aquellos proyectos o actividades que encontrándose obligadas a someterse al SEIA no lo hicieron. En concreto, en lo que respecta al régimen de responsabilidad por daño ambiental, lo que se debe esclarecer es: el hecho de haber incumplido la obligación legal de ingresar un determinado proyecto o actividad al SEIA ¿genera consecuencias jurídicas para el titular con respecto a los daños ambientales que ocasione su proyecto o actividad?

Pensamos que la única consecuencia jurídica que dicho incumplimiento presenta es que da origen a la situación prevista en el inciso $1^{\circ}$ del artículo 52 de la LBGMA, ya que estaríamos ante la infracción de una norma de protección ambiental establecida en la propia LBGMA (el artículo 8 en concreto $)^{3}$, y por lo tanto la culpa o dolo del titular de la actividad deberá ser presumida legalmente.

${ }^{1}$ La regulación del Sistema de Evaluación Ambiental en Chile puede comprenderse a partir de la lectura de los artículos 2 literal j), 8, 10, y 11 de la LBGMA.

${ }^{2}$ Corral, Hernán, El sistema de impacto ambiental y la responsabilidad civil por daño al medio ambiente, en Revista de Derecho Administrativo Económico 1 (1999) 1, p. 85 .

${ }^{3}$ En el mismo sentido, Corral, Hernán, cit. (n. 2), p. 85. 
2. Daños ambientales ocasionados por actividades que, estando obligadas, sí ingresaron al SELA

2.1. Efectos significativamente adversos para el medio ambiente pronosticados y autorizados en la Evaluación de Impacto Ambiental (EIA). - En esta hipótesis, el proceso de evaluación ambiental detectó que el proyecto o actividad generaría efectos significativamente adversos para el medio ambiente; sin embargo, estimó que los mismos podían ser reparados, compensados o mitigados mediante mecanismos diversos a la responsabilidad que la propia LBGMA y su reglamento contemplan.

Creemos que lo primero que se debe determinar es si en estos casos estamos o no frente a verdaderos daños ecológicos puros, en tanto la LBGMA denomina a este tipo de hechos lesivos como efectos significativamente adversos [artículos 2 letra i); 11 letra b) y e]; y no como daños ambientales [artículo 2 letra e)].

El tema en cuestión no es trivial, ya que siendo el daño un fenómeno proscrito por el ordenamiento jurídico, éste no podría (o no debería) ser autorizado por un órgano Administrativo bajo ninguna circunstancia y mucho menos tratándose de daños ambientales, pues recordemos que, como hemos señalado en otro lugar, un recurso ambiental dañado es un elemento dañador en sí mismo ${ }^{4}$.

De hecho, pensamos que esta circunstancia demuestra la necesidad de realizar una estricta diferenciación, al menos en lo que respecta a la LBGMA, entre los conceptos de daño ambiental, impacto ambiental $^{5}$ y contaminación ${ }^{6}$, por cuanto éstas dos últimas categorías sí son permitidas o toleradas por el ordenamiento jurídico ambiental, desde que tratándose de los impactos ambientales ${ }^{7}$ estos resultan en ocasiones inevitables para permitir el desarrollo de proyectos, mientras que la contaminación no es posible nunca eliminarla del todo ${ }^{8}$.

${ }^{4}$ FEMENías, Jorge, El régimen general de responsabilidad por daño ambiental en la ley $n^{\circ} 19.300$ Sobre Bases Generales del Medio Ambiente. Un análisis de sus normas a la luz de los principios del derecho ambiental (Valladolid/Santiago, Tesis para optar al Grado de Doctor en Derecho, Universidad de Valladolid - Pontificia Universidad Católica de Chile, [inédita], 2016), p. 382.

5 Sobre el particular, Astorga, Eduardo, Derecho ambiental chileno. Parte General (3a edición, Santiago, Abeledo Perrot - Thomson Reuters, 2012), p. 48. Definida en el artículo 2 letra k) de la LBGMA.

${ }^{6}$ Definida en el artículo 2 letra c) de la LBGMA.

${ }^{7} \mathrm{Al}$ respecto, Silva, Beatriz, Evaluación Ambiental: Impacto y Daño. Un Análisis Jurídico Desde la Perspectiva Cientifica (Alicante, Tesis para optar al grado de Doctor en Derecho, Universidad de Alicante, [inédita], 2012), p. 58.

8 Actas Oficiales de la Comisión Constituyente, sesión 182a a celebrada en 
Pero ocurre que, al parecer, en la hipótesis que venimos analizando estaríamos frente a situaciones donde la LBGMA, con el objeto de permitir el desarrollo de proyectos o actividades, autoriza determinados daños ambientales -y no impactos ambientales-, ya sea por estimar que éstos pueden ser minimizados a límites tolerables, reparados o bien compensados con otras medidas que representan un valor ambiental similar o mayor.

Lo anterior se indica dado que la denominación efectos significativamente adversos aparenta ser un género al cual pertenece la especie daño ambiental. En efecto, siendo éste último definido por la LBGMA como "toda pérdida, disminución, detrimento o menoscabo significativo inferido al medio ambiente o a uno o más de sus componentes", no cabe duda alguna que bajo dichas notas distintivas pueda también ser considerado o catalogado como un efecto significativamente adverso inferido al medio ambiente.

En este escenario, es posible advertir una distinción entre daño ambiental, impacto ambiental y contaminación ${ }^{9}$. Pero no ocurre lo mismo entre las nociones de daño ambiental y efectos significativamente adversos de los que habla la ley al referirse a los EIA, donde cuesta visualizar elementos que permitan diferenciarlos y, por el contrario, más bien parece tratarse de fenómenos vinculados en una relación de géneroespecie $^{10}$.

Expresado el problema en los términos expuestos, creemos que existen dos interpretaciones posibles para resolver esta cuestión: a) aquella que niega el carácter de daño ambiental a los denominados efectos significativos adversos por la LBGMA; y, b) aquella que entiende que ambos términos son sinónimos y, en consecuencia, los señalados efectos significativamente adversos serían daños ambientales permitidos por el ordenamiento jurídico ambiental.

a) Interpretación según la cual se niega que los efectos significativamente adversos autorizados por la Evaluación Ambiental correspondan a daños ambientales. - Bajo esta visión surgen dos consecuencias elementales: Primero, los efectos significativamente adversos que fueron autorizados por la Resolución de Calificación Ambiental (RCA) que calificó ambientalmente favorable el proyecto o actividad, no pueden dar origen

miércoles 14 de enero de 1976. [visible en internet: http://www.bcn.cl/lc/cpoliti$\mathrm{ca} /$ constitucion_politica/Actas_comision_ortuzar/Tomo_VI_Comision_Ortuzar. pdf.]

${ }^{9} \mathrm{E}$ incluso, con la sola lectura del artículo 2 letra i), queda claro que para la LBGMA “impacto ambiental y efecto significativamente adverso" no son lo mismo.

${ }^{10}$ Sobre este punto, resulta interesante la opinión de Corral, Hernán, cit. (n. 2), p. 87. 
a responsabilidad por daño ambiental, en tanto los mismos no configuran un daño ecológico puro y deben ser corregidos, mitigados o compensados, a través de los mecanismos que la propia LBGMA contempla y que se refieren, fundamentalmente, a la implementación de las medidas que el titular propuso y que la autoridad administrativa pertinente aprobó; y, segundo, la autoridad administrativa no puede autorizar la generación de daños ambientales -entendiendo por tales aquellos que reúnan las características expresamente establecidas en la definición que de ellos proporciona la LBGMA-. En tal sentido, si éstos se verifican en el desarrollo de un proyecto o actividad que fue sometida al SEIA, necesariamente serán daños ambientales no au torizados que deberán ser reparados conforme se expondrá más adelante.

Existe doctrina que denuncia una contradicción en la LBGMA o en su reglamento, ya que no consideraron una compaginación entre los daños autorizados por la Autoridad pública y la responsabilidad medioambiental, en cuanto ésta última -por disponerlo así los artículos 3 y 51 de la LBGMA- ordena que todo aquel que causa culpable o dolosamente un daño al medio ambiente deba repararlo ${ }^{11}$. Sin embargo, estimamos que dicha contradicción se evita por medio del análisis precedente.

En efecto, examinado el problema desde la perspectiva que exponemos, tal contradicción no se verifica por cuanto, siguiendo la lógica que infunde a la LBGMA, todo daño ambiental deberá ser reparado, mientras que aquellos efectos lesivos que no pueden ser calificados como tal por encontrarse previamente ponderados y autorizados por la autoridad administrativa -aunque reúnan algunas de las características del daño ecológico puro- podrán ser perfectamente compensados, mitigados o corregidos en conformidad al mecanismo pertinente establecido por la propia LBGMA y por el Reglamento del SEIA.

b) Interpretación según la cual se afirma que los efectos significativamente adversos son daños ambientales autorizados en la Evaluación Ambiental respectiva. - Resulta inevitable reconocer que una interpretación como la anterior parece bastante forzosa y consiste más bien en un esfuerzo dogmático para hacer coherente la sistemática de la LBGMA que en una propuesta real que solucione los problemas que presenta la materia en análisis.

Por ello, aunque pensemos que desde la perspectiva de la teoría del derecho $^{12}$ ello no resulta correcto, conforme el tenor expreso de las

${ }^{11}$ Corral, Hernán, cit. (n. 2), p. 88.

${ }^{12}$ Como lo ha reconocido nuestra Corte Suprema: Quinto: El daño es connaturalmente perjudicial, malicioso, perverso. Siempre "echa a perder»o «estropea» (Excma. Corte Suprema, causa rol No 10.884 - 2011, sentencia de 4-12-2012, caratulada 
normas de la LBGMA, nos parece que se debe concluir que este cuerpo normativo sí permite la producción de ciertos daños ambientales a los que denomina eufemísticamente efectos significativamente adversos. Como afirma una autora, "se trata, en muchos casos, de daños ambientales (afectaciones significativas) pero que estarán justificadas por nuestra legislación, ya que en sede administrativa se le exigirá mitigar, reparar o compensar" 13 .

En consecuencia, se trataría de daños ambientales cuya reparación se previene mediante un mecanismo que excluye la responsabilidad, el que se traduce en una evaluación ambiental de ellos y en la implementación de las medidas pertinentes para hacerles frente, a saber, de mitigación, reparación o compensación. Todo, bajo la lógica del principio del desarrollo sostenible, esto es, "aquél que satisface las necesidades de las generaciones presentes sin comprometer la capacidad de las futuras para satisfacer las suyas"14.

Bajo este prisma, surge la pregunta ¿qué ocurre con estos daños ambientales con respecto al régimen de responsabilidad regulado en la LBGMA? pareciéndonos que, en esta hipótesis, haber obrado en forma plenamente ajustada a una autorización administrativa especial, que ha sido enderezada a regular, controlar y reparar daños ambientales que luego se verificaron, configura una causal de justificación en la medida que los mentados daños hayan sido mitigados, reparados o compensados conforme a dicha autorización. Luego, si dicha mitigación, reparación o compensación no se verifica, habrá lugar entonces a exigir la responsabilidad por daño ambiental de su autor.

\subsection{Daños ambientales pronosticados por la Evaluación Ambiental y} expresamente prohibidos o no autorizados. - Aquí estamos frente a situaciones donde la evaluación ambiental detectó que el proyecto o actividad ocasionaría ciertos daños ecológicos puros que prohibió, razón por la cual se obligó al titular a ejecutar una serie de medidas tendientes a evitarlos.

$\mathrm{Al}$ respecto, nos parece que verificados daños que fueron expresamente prohibidos en la evaluación ambiental e imponiéndose al titular del pro-

"Fisco de Chile con Servicio de Vertederos Los Maitenes"). En tal sentido, nos parece que el derecho no puede tolerar ninguna forma de daño bajo ninguna hipótesis.

${ }^{13}$ Delgado, Verónica, La responsabilidad civil extracontractual por el daño ambiental causado en la construcción u operación de las carreteras, en Revista de Derecho Universidad Austral de Chile 1 (2012) 25, p. 69.

${ }^{14}$ Betancor, Andrés, Derecho Ambiental (Madrid, La Ley, 2014), p. 179. En España, una opinión similar es la que sostiene CONDE, Jesús, El deber jurídico de restauración ambiental (Granada, Editorial Comares, 2004), p. 267. 
yecto o actividad que los ocasionó una serie de condiciones y medidas para evitarlos, éste se encontrará obligado a su reparación.

En todo caso, un correcto análisis de esta hipótesis requiere efectuar una distinción previa en torno a si las medidas impuestas en la respectiva RCA se ejecutaron, o no, en conformidad a lo dispuesto en ella.

Pensamos que en el evento que las medidas no se hayan ejecutado conforme a lo dispuesto en la RCA es posible aplicar en contra del titular del proyecto o actividad la presunción del artículo 52 inciso $1^{\circ}$ de la LBGMA, por cuanto se trata de la infracción a normas de protección, preservación o conservación ambientales, establecidas en la propia LBGMA. En concreto, se trataría de una infracción al artículo 24 inciso final. Asimismo, porque con ello el titular infringe el artículo 35 literal a) de la LOSMA, la cual es una norma de protección ambiental establecida en otra disposición legal.

Finalmente, si las medidas sí fueron adoptadas conforme a lo previsto por la RCA pero igualmente se verificó un daño ambiental, creemos que respecto del titular del proyecto o actividad no se configura la presunción del artículo 52 mencionado, pero que este igualmente podría ser considerado responsable de la reparación de dichos daños ambientales, en la medida que se acrediten todos los presupuestos de la responsabilidad por daño ambiental - entre los que se cuenta, desde luego, su culpa o dolo ${ }^{15}$.

Lo anterior se piensa, dado que la autorización estatal debe considerarse principalmente como un medio de control o medida preventiva y no como garantía de irresponsabilidad ${ }^{16}$, o, al menos, ello no puede constituir una regla general.

En efecto, a nuestro juicio, "el cuidado empleado por el empresario no se encuentra consumado, toda vez, que el mandato general de actuar conforme a la diligencia exigible, le imponía el deber de ejecutar y soportar las medidas necesarias para no producir el daño, aun por sobre las requeridas por la resolución de tutela ambiental, y que vienen determinadas por las circunstancias del lugar, tiempo, persona, previsibilidad, riesgo, trascendencia técnica, costo de evitación, entre otros criterios homologables, objeto siempre de una definición prudencial del sentenciador"17, lo que se acentúa al tratarse de daños previstos y expresamente prohibidos

${ }^{15}$ Contra esta opinión, Corral, Hernán, cit. (n. 2), p. 88.

16 JanA, Andrés, La responsabilidad Civil en el Proyecto de Bases del Medio Ambiente, en Revista Derecho y Humanidades 1 (1992) 2, p. 188.

${ }_{17}$ Hunter, Iván, La culpa con la ley en la responsabilidad civil ambiental, en Revista de Derecho (2005), p. 6. [visible en internet: http://mingaonline.uach.cl/ scielo.php?pid $=S 071809502005000200001 \&$ script $=$ sci_arttext $]$ 
por la resolución que calificó ambientalmente favorable su proyecto o actividad. ${ }^{18}$ Así también ha sido resuelto por nuestra Corte Suprema ${ }^{19}$.

Asimismo, y sin perjuicio de la responsabilidad que pesará sobre él, creemos que se deberá analizar si las medidas impuestas por la Autoridad administrativa fueron realmente idóneas, pues en caso que no lo hayan sido, se debe evaluar la concurrencia de responsabilidad de la Administración pública por haber efectuado una deficiente evaluación ambiental.

Como se ha afirmado, "no debe olvidarse que la actividad, aunque privada, se somete a autorización, cuya justificación se encuentra en la necesidad de que la Administración controle su ejercicio, por entrañar un potencial dañoso para la sociedad. Desde esa perspectiva, tampoco cabe excluir por completo la responsabilidad patrimonial de la Administración cuando los perjuicios resulten del deficiente ejercicio de sus competencias, al otorgar la autorización (culpa in eligendo), o al inspeccionar y controlar el desarrollado de la actividad autorizada (culpa in vigilando)" "20. Al contrario, "la protección del medio está precisamente en la base de una intensa intervención pública, que -en gran medida- se articula a través de autorizaciones"21.

En lo que a nuestro parecer respecta, creemos que una situación como la señalada puede engendrar responsabilidad para la Administración pública, en tanto se configura una culpa por omisión de su función de control o protección ambiental ${ }^{22}$.

En efecto, éste es un caso de imputación de responsabilidad a la Administración pública, por los daños causados por particulares, con fundamento en haber autorizado la apertura de esos establecimientos y no vigilar el cumplimiento de la normativa ambiental, omitiendo así su deber de control y vigilancia. La administración tiene la potestad de control de las actividades al otorgar las correspondientes licencias administrativas y la obligación de imponer las medidas correctoras necesarias y, en caso de

${ }^{18}$ En un sentido similar, Moreno, Eulalia, La protección jurídico-privada del medio ambiente responsabilidad por su deterioro, (Granada, Tesis para optar al Grado de Doctor en Derecho, Universidad de Granada, [inédita], 1990), p. 359.

19 Excma. Corte Suprema, causa rol N³96 - 2009, sentencia de 20-04-2011, caratulada "Asociación de Canalistas del Embalse Pitama con Sociedad Concesionaria Rutas del Pacífico S.A.”, disponible en: Legal Publishing $\mathrm{N}^{\circ}$ identificador: CL/ JUR/3422/2011.

${ }^{20}$ Laguna DE PAZ, José Carlos, La autorización administrativa (Navarra, Thomson Civitas, 2006), p. 300.

${ }^{21}$ Laguna de PaZ, José Carlos, Responsabilidad de la Administración por daños ambientales, en Noticias de las Unión Europea 305 (2010), p. 74.

${ }^{22}$ Contra esta posibilidad, Cordero, Encarna, Derecho de daños y medio ambiente, ahora, en Ortega Álvarez, Luis (director), Lecciones de Derecho del Medio Ambiente (4a edición, Valladolid, Lex Nova, 2005), pp. 525 y 526. 
incumplimiento de las condiciones impuestas, suspender el funcionamiento de la actividad, revocar la licencia o imponer sanciones ${ }^{23}$.

De esta forma, podría sostenerse que, como afirma VÁZQUEZ DE PRADA, “implícitamente, el ente público concedente de la autorización se responsabiliza de todas las perturbaciones ambientales introducidas por dicha autorización"24.

Dado que este último tema será abordado en el acápite inmediatamente siguiente, nos remitiremos a lo que, mutatis mutandi, sobre el particular diremos a continuación cuando hablemos de los daños ambientales no previstos por la evaluación ambiental.

\subsection{Daños ambientales que no fueron pronosticados en la Evaluación de} Impacto Ambiental. Uno de los problemas más interesantes que se presentan en esta materia, dice relación con aquellos daños ecológicos puros que surgen a consecuencia de acciones realizadas en el marco de dichos proyectos o actividades y que no fueron pronosticados o proyectados durante todo el proceso de evaluación ambiental.

En este caso, estamos frente a situaciones donde se ha verificado un daño ambiental que no fue visualizado ni por la autoridad-que finalmente autorizó el mentado proyecto o actividad- ni por el titular de éstos - que fue quien proporcionó todos los antecedentes ante la Autoridad administrativa para ser evaluados.

Luego, a efectos de determinar el responsable de la reparación de los daños ambientales no previstos ocasionados por un proyecto o actividad evaluado ambientalmente favorable por la Autoridad administrativa, se deberán resolver las siguientes inquietudes: ¿es posible hacer responsable al titular que sometió su proyecto a una evaluación ambiental, que concluyó con una calificación favorable, sin haber previsto los daños ambientales que finalmente ocasionó?; y ¿es posible perseguir la responsabilidad de la Administración por haber incurrido en una deficiente evaluación ambiental al no haber previsto ese concreto daño?

\footnotetext{
${ }^{23}$ Una posición aún más dura es la que sostiene CONDE, Jesús, cit. (n. 14), p. 370.

${ }^{24}$ Vázquez de Prada, Valentín, Medio Ambiente y costes de contaminación, en Documentación Administrativa 178 (1978), pp. 151 y ss. En un sentido similar, JoRDANo, Jesús, La responsabilidad de la Administración con ocasión de los daños al medio ambiente, en Revista de Derecho Urbanistico 119 (1990), pp. 99 y ss. El autor morigera su opinión más tarde. JORDANO, Jesús, Administración y responsabilidad por daños al medio ambiente: La construcción del régimen jurídico de los daños ambientales, ahora, en RuIz-Rico RuIz, Gerardo (director), La protección jurisdiccional del medio ambiente (Madrid, Consejo General del Poder Judicial. Cuadernos de Derecho Judicial, 2001), pp. 283-284.
} 
Para resolver estos problemas creemos que es necesario realizar nuevamente una distinción según si los daños no pronosticados en la Evaluación Ambiental eran previsibles o imprevisibles. Por la extensión que exige su tratamiento, nos ocupamos de esta materia en los números 2.4 y siguientes.

\subsection{La responsabilidad del titular del proyecto o actividad en} aquellas hipótesis en que los daños ambientales no pronosticados si eran previsibles. — Pensamos que en éstas hipótesis, "estos daños no quedarán salvaguardados por la certificación estatal de cumplimiento de la legislación, ya que el titular del proyecto o actividad no ha integrado a la evaluación administrativa la información y descripción, correcta y completa de la actividad que pretendió desarrollar; aquí, la sola autorización del poder público no exime de responsabilidad al agente y es perfectamente posible seguir el camino de la imputación subjetiva de culpabilidad para hacer efectiva la responsabilidad ambiental" 25 .

Es decir, en los casos en que se produzcan daños no previstos en la evaluación ambiental, pero que debieron serlo (daños previsibles), el titular del proyecto o actividad que los ocasionó debe responder por ellos.

Lo anterior se indica, en primer lugar, por la propia lógica del SEIA. En efecto, en la evaluación ambiental a la que se someten ciertos proyectos o actividades es el propio interesado quien acompaña a la Autoridad respectiva (SEA) todos los antecedentes necesarios para que dicho organismo pueda coordinar con los respectivos órganos sectoriales (Dirección General de Aguas, Servicio Agrícola y Ganadero, Consejo de Monumentos Nacionales, etc.) el pronunciamiento sobre la conformidad, o no, del proyecto con la normativa ambiental vigente en nuestro país ${ }^{26}$.

En tal sentido, es el particular quien pone a disposición de la Autoridad toda la información necesaria para que esta pueda evaluar su proyecto, siendo en consecuencia él, el principal responsable por la veracidad y completitud de la misma.

De allí que la falta de previsión de un eventual daño ambiental es un yerro que principia, fundamental y eminentemente, en el titular del proyecto o actividad, pues es él quien, siendo el interesado en llevarlos a cabo, debe evaluar cada una de las situaciones de riesgo que presente su desarrollo empresarial.

Así, por lo demás, lo impone la observancia de los principios preven-

${ }^{25}$ Hunter, Iván, cit. (n. 17), p. 7.

${ }_{26}$ Artículo 8 de la LBGMA. Para una síntesis del procedimiento, Astorga, Eduardo, cit. (n. 5), pp. 183-189. 
tivo y precautorio, según hemos dicho en otra oportunidad ${ }^{27}$, en virtud de los cuales, si no existe una certeza suficientemente contundente de que la actividad no ocasionará daño, a la luz de los estudios científicos y el estado actual del arte, el individuo interesado en llevarla a cabo deberá abstenerse de hacerlo.

De esta forma, puede considerarse suficiente que el daño sea previsible en abstracto, sin que tenga que haber previsto las consecuencias precisas de su acción, sino un daño dentro de cierta categoría, como, por ejemplo, la posibilidad de causar un daño ecológico puro a las aguas o al aire. ${ }^{28}$

En segundo lugar, y en sintonía con lo expuesto en precedencia, porque es el titular del proyecto o actividad el experto que mejor conoce los alcances de su empresa y, por lo tanto, de los impactos y daños ambientales que la misma puede generar. En tal sentido y también en armonía con los postulados del principio precautorio, es él quien tiene la primera obligación de anteponerse a cualquier situación de riesgo que pueda devenir en un daño ambiental ${ }^{29}$. Así también lo ha resuelto nuestra Corte Suprema ${ }^{30}$.

Pero, es más, confluye también en estos casos el principal mandato del principio contaminador pagador, esto es, que el causante del daño ambiental sea fundamentalmente quien deba repararlo ${ }^{31}$. En efecto, en virtud de los preceptos que impone este principio, es posible sostener que el titular de la actividad debe responder también por los daños no previstos pero que resultaban previsibles, por cuanto es él quien creó las condiciones para que se produzca el deterioro al medio ambiente.

En tal sentido, y en aplicación armónica de las dos fases del sobredicho principio $^{32}$, no resulta ajustado a derecho pretender que sea la sociedad la que cargue con los costos ambientales de una actividad empresarial

${ }^{27}$ FeMENÍAS, Jorge, cit. (n. 4), pp. 114-382.

${ }^{28}$ Ruda, Albert, El Daño Ecológico Puro. La Responsabilidad Civil por el deterioro al Medio Ambiente, con especial atención a la Ley 26/2007, de 23 de octubre, de Responsabilidad Medioambiental (Navarra, Thomson Aranzadi, 2008), p. 415.

${ }^{29}$ En esta misma línea de pensamiento, BANFI DEL Río, Cristián, De la responsabilidad civil como instrumento de protección ambiental, en Revista Chilena de Derecho Privado Fernando Fueyo Laneri 2 (2004), p. 48.

${ }^{30}$ Excma. Corte Suprema, causa rol 396 - 2009, sentencia de fecha 20-04-2011, caratulada "Asociación de Canalistas del Embalse Pitama con Sociedad Concesionaria Rutas del Pacífico S.A.”disponible en: Legal Publishing $N^{\circ}$ identificador: CL/ JUR/3422/2011. Este mismo criterio ya había sido sostenido por la Iltma. Corte de Apelaciones de Puerto Montt, causa rol No 11.652 - 2003, sentencia de fecha 2-042004, caratulada "Fisco de Chile con Cía. Industrial Puerto Montt S.A.”.

${ }^{31}$ En un sentido similar al nuestro, Delgado, Verónica, cit. (n. 13), p. 70.

${ }^{32}$ Femenías, Jorge, cit. (n. 4), pp.130-145. 
desarrollada por un sujeto, quien, además, se beneficiará en forma predominante con los provechos económicos de ésta.

En efecto, el daño ecológico puro es un daño colectivo, razón por la cual puede engendrar costos al colectivo social. De esta manera, excluir la responsabilidad del titular del proyecto o actividad en situaciones como la que venimos estudiando, podría malograr financiaciones públicas o dejar a la Administración en la necesidad que se efectúen otras para reparar el daño ambiental. En este sentido, los postulados del principio permiten justificar que sea el autor del daño quien asuma esos costos y no la sociedad indiscriminadamente considerada.

Se debe recordar, además, que la faz restauradora del principio contaminador pagador dispone que todo daño ambiental hace surgir una consecuencia jurídica para el autor del daño ambiental, la que se traduce en que éste será responsable de todos los costos que ésta genera. El daño ecológico puro, acorde al principio, da origen a la obligación de soportar todas las consecuencias y, en particular, los costos de la reparación.

En síntesis, en estas hipótesis, la culpa se puede verificar si el titular del proyecto o actividad: i) no se comportó como debió haberlo hecho; ii) hizo menos de lo que se encontraba obligado -por imponérselo el ordenamiento ambiental en su conjunto, normas y principios-; iii) no actuó como un hombre prudente de acuerdo al estándar que el Derecho ambiental y los principios que lo informan le exigían; $y / o, i v)$ fue incapaz de prever los daños ambientales que el estado de los conocimientos científicos y la mejor tecnología disponible permitían predecir ${ }^{33}$.

$\mathrm{Al}$ respecto, se debe recordar que para la construcción del estándar de diligencia para apreciar la culpa o el dolo del titular del proyecto o actividad, el juez debe considerar los postulados de los principios preventivo y precautorio - según si los riesgos y peligros eran o no conocidos respectivamente ${ }^{34}$, y en tal sentido quienes realizan ciertas actividades que importan una consecuencia o un riesgo que -aunque sea potencialmentepuede ocasionar un daño ambiental, deben, en virtud de estos principios, tomar mayores medidas de prevención u observar una mayor diligencia si quieren eximirse de responsabilidad. De esta manera, pesan sobre estos individuos deberes de información y de previsión mucho más rigurosos.

2.5. La responsabilidad de la Administración por deficiencias en la Evaluación Ambiental: Hipótesis en que los daños ambientales no pronosticados que ocasionó el titular del proyecto o

${ }^{33}$ Hunter, Ivan, cit. (n. 17), p. 7.

${ }^{34}$ Femenías, Jorge, cit. (n. 4), pp. 157 y 178. 
actividad sí eran previsibles. - Examinaremos separadamente cada uno de los extremos de este punto (letras $a-b$ ).

a) Eventual responsabilidad en la que podría incurrir la Administración por haber llevado a cabo una defectuosa evaluación ambiental que tuvo como consecuencia la verificación de daños ecológicos puros no previstos por ella. Antes de efectuar cualquier análisis, es importante advertir que en este apartado no se estudiará la responsabilidad que le pueda caber a la Administración pública por los daños que con su acción (u omisión) el titular de la RCA haya ocasionado a particulares con ocasión del daño ecológico puro que generó (daños civiles derivados del mismo hecho que ocasionó el daño ambiental), pues éstos, según hemos señalado en otro lugar ${ }^{35}$, se regirán por el Derecho común y general -en este caso, por el estatuto particular de responsabilidad patrimonial de la Administración del Estado ${ }^{36}$.

Por el contrario, el caso en examen se refiere a la posibilidad de perseguir la responsabilidad por daño ambiental de la Administración pública y, más concretamente, aquella responsabilidad que le cabría por haber efectuado una mala o deficiente evaluación ambiental y, en definitiva, haber contribuido en la causación de un daño ecológico puro. En tal sentido, estudiaremos la posibilidad de poder demandar/ requerir directamente a la Administración del Estado la reparación de daños medioambientales ocasionados materialmente por el sujeto al cual ella autorizó mediante la correspondiente RCA.

Sobre este punto, hacemos también presente que no se analizarán en este apartado los problemas de legitimación que una hipótesis como la que se indica pueda ocasionar - específicamente, si es posible, como se pregunta BERMúdez Soto ${ }^{37}$, la existencia de un litigio de reparación ambiental caratulado Fisco con Fis $\mathrm{co}^{38}$ - por cuanto dicho problema excede los límites de este trabajo, al referirse a cuestiones de Derecho adjetivo.

De tal suerte, lo que se buscará elucidar en estas páginas es si resulta posible perseguir la responsabilidad por daño ambiental de la Adminis-

${ }^{35}$ Femenías, Jorge, cit. (n. 4), pp. 62-66; 91-108; 233-302.

36 Ver los artículos 4 y 42 del Decreto con Fuerza de Ley No 1, Ministerio Secretaria General de la Presidencia, 13 de diciembre del 2000, D. of de 17 de noviembre de 2001, que fija texto refundido, coordinado y sistematizado de la Ley No 18.575, Orgánica Constitucional de Bases Generales de la Administración del Estado [en adelante LBGAE], en relación a lo dispuesto en los artículos 6, 7 y 38 de la CPR. Asimismo, por el artículo 141 de la LOCM en los casos que corresponda.

${ }^{37}$ Bermúdez, Jorge, Fundamentos de Derecho Ambiental (2a edición, Valparaíso, Ediciones Universitarias Universidad Católica de Valparaíso, 2014), pp.439 y ss.

38 Dado que el Estado es uno de los titulares de la acción de reparación ambiental. 
tración pública por la actuación del tercero autorizado, esto es, por los daños ambientales que ha ocasionado el titular de un proyecto o actividad que fue calificado ambientalmente favorable por ella ${ }^{39}$.

b) Hipótesis especificas de responsabilidad de la Administración que se pretenden analizar. - En este estado de cosas, las hipótesis de responsabilidad de la Administración que nos interesa estudiar ${ }^{40}$ se refieren a aquellos casos en que se ocasionó un daño ecológico puro que no fue pronosticado en la evaluación ambiental, pero que era perfectamente previsible, y donde dicha falta de previsión se ha debido a que la Administración pública (tanto el SEA como la Comisión [en adelante la Comisión] a que se refiere el inciso $1^{\circ}$ del artículo 86 de la $\left.\mathrm{LBGMA}^{41}\right)$ : o bien efectuó mal o negligentemente la evaluación ambiental en cuya virtud se calificó ambientalmente favorable el proyecto o actividad que ocasionó un determinado daño ecológico puro; o bien, el caso más grave, no llevó a cabo la evaluación pertinente, calificando ambientalmente favorable el proyecto, que produjo un determinado daño ambiental, sin haberlo examinado ${ }^{42}$.

En este escenario, y respecto de ambas situaciones, pensamos que resulta plenamente viable exigir la responsabilidad de la Administración pública $^{43}$, la cual se verifica en que concurre respecto de ella una especial

39 Un análisis en el Derecho comparado de este problema puede verse en MARTín, Luis, Medio Ambiente y responsabilidad de la Administración, en Revista Española de Derecho Administrativo 11 (1988), pp. 651 y ss. En un sentido similar, CondE, Jesús, cit. (n. 14) p. 354.

40 Para un estudio de las diversas hipótesis que pueden dar lugar a demandar la responsabilidad de la Administración pública, CONDE, Jesús, cit. (n. 14), pp. 369 y ss. También se debe considerar que pueden presentarse situaciones de concurrencia de responsabilidad de varias Administraciones. Sobre el particular, GALERA, Susana, La responsabilidad de las administraciones públicas en la prevención de daños ambientales (Madrid, Ediciones Montecorvo, 2001), pp. 151 y ss.

${ }^{41}$ Ver el inciso $1^{\circ}$ del artículo 86 de la LBGMA.

${ }^{42}$ Sobre el particular, es interesante destacar que, en España, por ejemplo, la responsabilidad patrimonial de la Administración es, teóricamente, objetiva (según lo dispone el artículo 139 de la Ley 30/1992), pero la doctrina, sin embargo, busca títulos de imputación en el ejercicio de sus funciones de control en la culpa (in vigilandi, in eligendo, etc.). Sobre este punto, Pantaleón, Fernando, Responsabilidad patrimonial de las Administraciones públicas: sobre la jurisdicción competente, ahora, en Martín Rebollo, Luis (director), Responsabilidad patrimonial de las Administraciones públicas. Cuadernos de Derecho Judicial (Madrid, Consejo General del Poder Judicial, 1996), p. 40; y, GARRIDO, Fernando, Los limites de la responsabilidad patrimonial: una propuesta de reforma legislativa, en Revista Española de Derecho Administrativo 94 (1997), pp. 178-179.

${ }^{43}$ Contra nuestra opinión, Pierry, Pedro, Responsabilidad del Estado por Daño Ambiental, ahora, en Silva Abranetto, Ximena (directora), Cumplimiento de la Le- 
forma culpa in ommitendo ${ }^{44}$ - en el fondo, se otorgó una autorización ambiental (acción), sin haber efectuado la evaluación ambiental pertinente o habiéndola efectuado en forma deficiente (omisión). Como expresa Rebollo Puig, la responsabilidad de la Administración se sustenta en "el incumplimiento de un deber de evitar que ese concreto agente causara daños o actuara de forma que pudiera causarlos, más una falta de diligencia para prevenirlos y evitarlos" $" 45$.

Para una y otra hipótesis, la circunstancia fáctica sobre la cual se fundamentaría la responsabilidad de la Autoridad administrativa, dice relación con que ésta no verificó el cumplimiento de todos y cada uno de los antecedentes que permitían asegurar que el proyecto o actividad cumplía con la normativa ambiental vigente, y debido a esto no advirtió ni previó que el desarrollo del proyecto empresarial necesariamente ocasionaría daños ecológicos puros. En concreto, "vulnera la obligación que pesa sobre ella de autorizar solamente aquellas actividades que reúnan las garantías necesarias" ${ }^{\prime 46}$.

c) Factores de imputación subjetivos. - En cuanto al factor subjetivo que permitiría imputar dicha responsabilidad a la administración, se deberá distinguir dos hipótesis. La primera es el comportamiento negligente en la evaluación ambiental, sin lugar a dudas el elemento subjetivo de imputación será la culpa en la que incurre la Administración en tanto se comporta negligentemente en el cumplimiento de sus deberes de fiscalización y

gislación Ambiental y Reparación de Daños al Medio Ambiente (Santiago, Consejo de Defensa del Estado, s.d.), pp. 77 y 79.

${ }^{44}$ Sobre las nociones de culpa in vigilando e in ommitendo de la Administración, Jiménez-Blanco Carrillo de Albornoz, Antonio, Responsabilidad Administrativa por culpa in vigilando o in commitendo en VV.AA, Gobierno y Administración en la Constitución (Madrid, Instituto de Estudios Fiscales, 1988), pp. 893-907.

${ }^{45}$ Rebollo, Martín, Servicios públicos concedidos y responsabilidad de la Administración: imputación o responsabilidad por el hecho de otro. Comentarios a la STS de 9 de mayo de 1989, en Poder Judicial 20 (1990), p. 50. Es también la opinión de Entrena, Rafael, Responsabilidad e inactividad de la Administración, ahora, en Martínez López-Muñiz, J. Luis - Calonge Velázquez, Antonio (coordinadores), La responsabilidad patrimonial de las Administraciones públicas. III Coloquio Hispano-Luso de Derecho Administrativo. Valladolid, 16-18 de octubre de 1997 (Madrid, Marcial Pons, 1999), p. 370. En un sentido aún más enérgico, GómEz, Marcos, La inactividad de la administración (4 ${ }^{\mathrm{a}}$ edición, Navarra, Aranzadi Thomson Reuters, 2011), pp. 1107-1136. Sobre este tema, también Laguna DE PAZ, José Carlos, La autorización, cit. (n. 20), p. 315., PANTAleÓN, Fernando, Los anteojos del civilista: hacía una revisión del régimen de responsabilidad patrimonial de las Administraciones públicas, en Documentación Administrativa 237-238 (1994), pp. 247 y 249

${ }^{46}$ Laguna de PAz, José Carlos, La autorización, cit. (n. 20), p. 307. 
análisis de los antecedentes proporcionados por el titular del proyecto o actividad que ocasionó el daño ambiental respectivo.

$\mathrm{Al}$ respecto, se debe recordar que sin perjuicio de ser el titular quien acompaña todos los documentos necesarios para la evaluación ambiental, la Autoridad pública (tanto el SEA, como los organismos sectoriales consultados en la evaluación ambiental y la propia Comisión a la que alude el artículo 86 de la LBGMA) son órganos expertos que, precisamente, cuentan con la pericia necesaria para percibir si dichos antecedentes son incompletos o no han considerado efectos significativamente adversos que constituirían daños ambientales al momento de ejecutarse el proyecto o actividad.

En tal sentido, una vez que se informa a la Autoridad administrativa, por parte del titular, de todas las particularidades del proyecto o actividad, incluida su línea de base ${ }^{47}$, habida consideración del carácter de técnicosexpertos de los órganos que serán consultados, no resultaría plausible admitir una exoneración de su responsabilidad por no haber recibido toda la información o haberla recibida en forma parcial tratándose de daños ambientales previsibles.

En efecto, precisamente por su condición de técnicos, dichos órganos públicos se encontraban en situación de conocer perfectamente qué antecedentes no proveídos por el titular resultaban rigurosamente necesarios para poder autorizar el proyecto o actividad respectivo, así como los daños ambientales previsiblemente verificables que no habían sido considerados en la respectiva Declaración de Impacto Ambiental (DIA) o EIA.

Con respecto a la segunda hipótesis que planteábamos, el factor de imputación subjetivo será derechamente el dolo con que obra la Administración. Desde luego, el no haber analizado los antecedentes ni efectuado la correspondiente evaluación ambiental que por mandato legal se encontraba obligada, implica que la autorización que se proporcionó al titular del proyecto o actividad que ocasionó el daño ambiental sea un comportamiento manifiestamente doloso, entendido éste como la aceptación voluntaria del ilícito con conciencia de la antijuridicidad de la acción ${ }^{48}$.

d) Fundamentos jurídicos de la responsabilidad de la Administración. — Asimismo, para ambos casos, se debe mencionar que el fundamento de Derecho positivo en virtud del cual se puede atribuir a la Administración pública responsabilidad y la consecuente obligación de reparación de los daños ambientales ocasionados por el tercero autorizado por ella, descansa, principal y eminentemente, en el mandato constitucional que pesa sobre

${ }^{47}$ Cfr. el artículo $2^{\circ}$ letra l) de la LBGMA.

${ }^{48}$ Barros, Enrique, Tratado de responsabilidad Extracontractual (Santiago, Editorial Jurídica de Chile, 2007), pp. 159-160. 
el Estado (art. $19 \mathrm{~N}^{\circ} 8$ de la CPR), en tanto la Carta Fundamental hace cargar sobre él el deber de tutelar la preservación de la naturaleza ${ }^{49}$.

En efecto, estimamos que si en virtud de este mandato constitucional el Estado deberá reparar el medio ambiente dañado incluso en todas aquellas hipótesis en que no sea posible determinar al sujeto responsable ${ }^{50}$, tanto más deberá hacerlo en aquellas situaciones donde su intervención ha sido un elemento causal determinante en la verificación del daño ambiental ${ }^{51}$.

En síntesis y a la luz de lo expuesto, estimamos que "en la mayoría de las ocasiones, el daño ambiental surge por una actuación administrativa culposa o negligente, omisiva de su deber de actuar en defensa del medio ambiente e infractora por tanto del deber de protección que le viene impuesto [constitucional y] legalmente, y divergente del fin de persecución del interés general, concretado en este caso en el mantenimiento de las cualidades ambientales (hablaríamos en estos supuestos de funcionamiento anormal)" $" 52$.

e) La relación de causalidad en esta precisa hipótesis de responsabilidad de la Administración. - En otra esfera de reflexiones, y con respecto a cualquier aprensión que se pudiera tener en relación a la existencia del vínculo causal que debe ligar a la actuación de la Administración con el concreto daño ambiental ocasionado por el tercero autorizado, es importante hacer notar que el nexo causal se presenta y viene determinado por la ausencia de diligencia debida de la Administración por autorizar una actividad sobre la base de unas condiciones que no fueron suficientes, al no haber previsto los daños ecológicos puros que finalmente se verificaron ${ }^{53}$. En tal sentido, si la imprevisibilidad, según veremos en el acápite siguiente, sirve

49 Sobre el medio ambiente como objeto de un derecho y un deber o valor colectivo constitucionalizado, en derecho comparado, Vid. BetanCor, Andrés, cit. (n. 14), pp. 489-557.

50 Sobre el particular, en Derecho comparado, Vid. GomIs, Lucia, Responsabilidad por Daños al Medio Ambiente (Navarra, Aranzadi, 1998), p. 258. En un sentido similar, CONDE, Jesús, cit. (n. 14), p. 100.

${ }^{51}$ Así también lo sostiene, en España, Conde, Jesús, cit. (n. 14), p. 358.

52 Conde, Jesús, cit. (n. 14), p. 358. Para una comprensión acabada de este punto, Parada, Ramón, Régimen Jurídico de las AdministracionesPúblicas y del procedimiento administrativo común. Estudio, comentarios y texto de la Ley 30/92 de 26 de noviembre (Madrid, Editorial Marcial Pons, 1993), p. 428, LaGUnA DE PAZ, José Carlos, Responsabilidad, cit. (n. 21), p. 41.

${ }^{53}$ En esta materia, resulta interesante la sentencia del Tribunal Supremo RJ 1996, 3644, sentencia de 30 - 04 - 1996, caratulada Manuel A.S con Ayuntamiento de Las Palmas de Gran Canaria. 
como eximente de responsabilidad de la Administración y del titular, la previsibilidad sirve como factor de imputación ${ }^{54}$.

En efecto, no se debe olvidar que "en el mundo del Derecho, la causación no puede abordarse sólo con arreglo a criterios materiales, sino fundamentalmente valorativos. No interesa el variado y desigual cúmulo de causas sin las cuales el resultado físicamente no se hubiera producido, sino sólo aquéllas que jurídicamente pueden considerarse relevantes. Se trata de encontrar una «causalidad jurídica», o lo que es lo mismo, una imputación objetiva, que permita referir jurídicamente el resultado dañoso a la conducta de un sujeto determinado" 55 .

Sin embargo, es necesario afirmar que el erario público no puede asumir todos los perjuicios que pueda originar el sujeto autorizado, sino sólo aquellos que -de acuerdo con la normativa sectorial aplicable- expresen una conexión razonable entre el daño y la ausente o negligente evaluación ambiental llevada a cabo por la Administración" ${ }^{56}$ : "El resultado ha de ser previsible y evitable en el curso normal de los acontecimientos, de manera que -a la vista de las circunstancias concurrentes- la conducta de la Administración pueda considerarse idónea para su producción". ${ }^{57}$

f) Régimen según el cual se debe perseguir la responsabilidad de la Administración por los daños ambientales que ocasione. - Otro tema que debe ser abordado en este apartado dice relación con esclarecer si la responsabilidad ambiental de la Administración pública se debe perseguir en conformidad a la LBGMA o bien mediante las normas propias que rigen la responsabilidad patrimonial de la Administración del Estado ${ }^{58}$.

El problema que al respecto se presenta ha sido analizado rigurosamente en nuestro país por BERMúdEZ SOTO, de manera tal que para la exposición del status quaestionis del problema nos remitiremos, fundamentalmente, a sus estudios sobre el particular ${ }^{59}$.

${ }^{54}$ Conde, Jesús, cit. (n. 14), p. 362.

${ }^{55}$ LaCruZ, José Luis, Elementos de Derecho Civil (Madrid, Dykinson, 1999), II, p. 488.

${ }^{56}$ Laguna de Paz, José Carlos, La autorización, cit. (n. 20), p. 319. En un sentido similar, Pantaleón, Fernando, Los anteojos, cit. (n. 45), pp. 239-254.

57 Laguna de Paz, José Carlos, La autorización, cit. (n. 20), pp. 319 - 320.

${ }^{58}$ Que, como señalábamos algunas páginas más atrás, se configura por las disposiciones de los artículos 4 y 42 de la LBGAE, en relación a lo dispuesto en los artículos 6, 7 y 38 de la CPR, así como, por el artículo 141 de la LOCM en los casos que corresponda.

59 BERMúdEZ, Jorge, La responsabilidad extracontractual de la administración del Estado por falta de servicio y por el daño ambiental, en Revista de Derecho de la Universidad Católica de Valparaíso 23 (2002), pp. 253 - 264; y, Bermúdez, Jorge, Fundamentos, cit. (n. 37), pp. $434-444$. 
En tal sentido, "el análisis de esta materia tiene como base, por una parte, el marco normativo que el legislador ha fijado para determinar la responsabilidad extracontractual del Estado administrador y por otra, el conjunto de disposiciones de la LBGMA referidas a la responsabilidad por daño ambiental" ${ }^{60}$. En concreto, se debe dilucidar si la responsabilidad de la Administración que hemos estudiado en estas páginas deberá ser perseguida conforme a las normas que componen su propio estatuto jurídico de responsabilidad o bien conforme a las normas de la LBGMA que establecen el régimen general u ordinario de responsabilidad por daño ambiental en nuestro ordenamiento jurídico.

El análisis de esta cuestión no es baladí. En efecto, el régimen de responsabilidad por daño ambiental establecido en la LBGMA es de carácter subjetivo, esto es, para la determinación de la responsabilidad y la resultante obligación de reparar el daño ambiental, es necesario que concurra respecto del sujeto pasivo, junto con la acción, la relación de causalidad y el daño, su culpa o dolo. Mientras que, tratándose de la responsabilidad de la Administración pública, el régimen de responsabilidad aplicable es por falta de servicio ${ }^{61}$.

En este entendido, como se advierte, resulta fundamental esclarecer bajo qué estatuto debe responder la Administración por los daños ambientales ocasionados por el tercero autorizado en las hipótesis que venimos estudiando en este acápite.

Sobre el particular, BERMÚDEZ afirma que el problema debe ser abordado considerando la supuesta autarquía del Derecho administrativo, esto es, reconociendo que se trata de un Derecho estatutario, referido a la normativa jurídica válida específicamente para regular a la Administración,

${ }^{60}$ Bermúdez, Jorge, Fundamentos, cit. (n. 37), p. 434.

${ }^{61}$ BARros, Enrique, cit. (n. 48), pp. 485 y ss. Sobre el particular, ver también, Pantaleón, Fernando, Los anteojos, cit. (n. 45), p. 251; SAnz, Iñigo, Criterios del Consejo de Europa y ordenamiento español: Algunos problemas, ahora, en MARTínEZ López-Muñiz, Martínez López - CAlonge VelázQuez, Antonio (coordinadores), La responsabilidad patrimonial de las Administraciones públicas. III Coloquio Hispano-Luso de Derecho Administrativo. Valladolid, 16-18 de octubre de 1997 (Madrid, Marcial Pons, 1999), pp. 59-76. Para un sector de la doctrina la responsabilidad patrimonial de la Administración es objetiva, sustentando su tesis en las normas de la CPR. Sobre el particular, Sото KLoss, Eduardo, Responsabilidad Administrativa Municipal, en Revista de Derecho y Jurisprudencia y Gaceta de los Tribunales 78 (1981) 1, pp. 39 y ss; y FIAMMA, Gustavo, La acción constitucional de responsabilidad y la responsabilidad por falta de servicio, en Revista Chilena de Derecho 16 (1989) 2, pp. 429 - 440 (en especial la página 435). 
lo cual implica que, en Chile, se encuentra sustraído en ciertos aspectos del Derecho común ${ }^{62}$.

En esta línea de análisis, el autor citado agrega que entre los elementos del concepto de Derecho administrativo se cuentan: $i$ ) que se trata de un derecho público; ii) que se trata del derecho de la Administración pública; iii) que la relación jurídico administrativa requiere la presencia de una Administración pública; $y, i v$ ) que se trata de un derecho en equilibrio ${ }^{63}$.

Luego, y a partir del análisis dichas características o elementos del Derecho administrativo, se plantea la inquietud sobre cuál es el régimen que se debe utilizar para perseguir la responsabilidad por los daños ambientales ocasionados por la Administración, arribando a la conclusión de que "el problema del ordenamiento jurídico aplicable frente a los casos de daños ambientales ocasionados por órganos de la Administración del Estado no está resuelto. Aquí se han planteado las dos probables soluciones [responder conforme a su estatuto o conforme a la LBGMA], sin embargo, ninguna de ellas es absoluta. La elaboración dogmática de un Derecho administrativo moderno tiende a la aplicación autónoma de las normas jurídico-administrativas, cuando ellas existen. Lo que conduciría a que, frente a los daños que ocasiona la Administración, de cualquier naturaleza que estos sean, se deberá perseguir la responsabilidad según las normas que regulan la responsabilidad extracontractual por falta de servicio del Estado administrador. Por su parte, la LBGMA ha establecido un sistema de responsabilidad específico, que atiende a las especiales características que plantea la protección ambiental y no al sujeto que causa el daño ambiental. Así, desde la perspectiva del bien jurídico protegido, el medio ambiente, aparece como mucho más adecuado optar por esta segunda opción. La elección por cualquiera de las dos soluciones plantea inconvenientes, e incluso más, es probable que la solución definitiva sólo venga dada por el legislador" ${ }^{\prime \prime}$.

En conformidad al análisis expuesto, por nuestra medida, pensamos que la responsabilidad de la Administración por los daños ambientales ocasio-

${ }^{62}$ Bermúdez, Jorge, Fundamentos, cit. (n. 37), p. 436. En este punto, es interesante notar que, en otros ordenamientos jurídicos, como el español, por ejemplo, el Derecho administrativo es el derecho común de la Administración pública por lo que se auto integra. No es especial respecto del Derecho civil y si se remite a él, debe hacerlo en forma expresa. Sobre el particular, por todos, GARCía ENTERRÍA y FERnÁndez, Tomás-Ramón, Curso de Derecho Administrativo (15a edición, Navarra, Civitas - Thomson Reuters, 2011), I, pp. 64-71.

${ }_{63}$ Bermúdez, Jorge, Fundamentos de Derecho, cit. (n. 37), pp. 437-438.

64 Ver al respecto, Bermúdez, Jorge, Fundamentos, cit. (n. 37), pp. 443-444. BERMÚdEZ, Jorge, La responsabilidad extracontractual, cit. (n. 59), p. 264. 
nados por el tercero autorizado por ella mediante la correspondiente RCA, debe ser perseguida a través del régimen general u ordinario establecido en la LBGMA - salvo, desde luego, que existan disposiciones especiales aplicables (artículo 51 inciso $2^{\circ}$ ).

Ello se piensa, toda vez que dicho cuerpo normativo dispone expresamente que "todo el que culposa o dolosamente cause daño ambiental, responderá del mismo en conformidad a la presente ley" (artículo 51 inciso $1^{\circ}$ ). Consecuentemente, y en aplicación del principio de especialidad, la disposición de la LBGMA debe ser rigurosamente respetada en cuanto al imperativo de que todo sujeto -incluida la Administración pública- que ocasiona un daño al medio ambiente debe repararlo en conformidad a ella.

Arribamos a una idéntica conclusión analizando el problema bajo la consideración de que la naturaleza jurídica del régimen establecido en la LBGMA es de carácter mixto, esto es, un régimen mestizo compuesto por elementos de Derecho público y Derecho privado.

Bajo esta esfera de análisis, no se presenta el problema de aplicar las normas de responsabilidad del Derecho civil a las actuaciones de la Administración. Por el contrario, se aplican normas que, ciertamente, constituyen un régimen autónomo e independiente del Derecho privado, y que sustraen a los sujetos pasivos -en este caso a la Administración pública- de la aplicación del Derecho común y general, respetando la autarquía del Derecho administrativo de la que habla BERMúDEZ ${ }^{65}$.

Existen otros dos argumentos más que expone la doctrina para inclinarse por esta solución. Así, uno de ellos es el argumento teleológico, en cuanto el legislador creó un sistema especial de responsabilidad por daño ecológico puro con unas connotaciones particulares, atendido el bien jurídico protegido: el medio ambiente; y el otro, dice relación con la circunstancia de que, a diferencia de lo que ocurre en la responsabilidad por falta de servicio de la Administración del Estado, donde la pretensión ejercida es normalmente una indemnización de perjuicios que sufre una persona, en la responsabilidad por daño ambiental se persigue como objeto único la reparación del medio ambiente dañado, es decir, posee una afectación estrictamente ambiental ${ }^{66}$.

g) Concurrencia de responsabilidad entre el tercero autorizado y la Auto-

${ }^{65}$ Para el autor que venimos citando, las características que definen esta rama del Derecho refieren a que: i) se trata de un Derecho público; ii) se trata del Derecho común de la Administración Pública; iii) la relación jurídico-administrativa requiere de una Administración pública; y, iv) se trata de un Derecho de equilibrio. BERMÚDEZ, Jorge, Derecho administrativo general ( 3 a edición, Santiago, LegalPublishing - Thomson Reuters, 2014), pp. 39-38.

${ }_{66}$ Bermúdez, Jorge, Fundamentos, cit. (n. 37), p. 439. 
ridad administrativa. - Existe una última cuestión que debe ser analizada y que se vincula al hecho que, tratándose de casos donde existirá una concurrencia de responsabilidad entre el tercero autorizado y la Administración pública, se deberá determinar cómo y en qué medida se reparti rá la responsabilidad entre ambos.

Creemos que en estos casos, es posible aplicar la regla de responsabilidad solidaria contenida en el artículo 2317 del Código Civil ${ }^{67}$, pues, como sostuvimos en otra ocasión, el rol y verdadero alcance de la remisión que el artículo 51 inciso $3^{\circ}$ efectúa a las normas del Código Civil, es precisamente permitir el recurso a esas normas cuando las mismas favorezcan la labor de reparación de los daños ambientales y, en ningún caso, cuando le pongan trabas o la perjudiquen.

En efecto, se trata de un caso de coparticipación en un mismo hecho sin concertación de voluntad o de propósitos donde simultáneamente concurren dos hechos negligentes en la comisión del daño ${ }^{68}$. En tal sentido, huelga decir que tratándose de casos en que sí exista esa concertación de voluntades -como si se otorgara la RCA sin efectuar la evaluación ambiental respectiva u omitiendo antecedentes relevantes a sabiendas de la Administración-, tanto mayor es la posibilidad de aplicar la regla de solidaridad ${ }^{69}$.

En tal sentido, el legitimado activo de la acción ambiental podrá decidir si dirigirse directamente contra la Administración, el titular o contra ambos indistintamente para exigir la reparación completa del daño ambiental, no siendo de su injerencia las relaciones internas que deban resolver Administración y administrado en relación a determinar quién debe soportar realmente y conforme a Derecho los costos de la reparación del daño ecológico puro en cuestión - es decir, no le atañe el problema de la contribución a las deudas.

b) Hipótesis en que los daños ambientales no pronosticados eran imprevisibles. - De la ausencia de responsabilidad del titular y de la administración. Finalmente, en estos casos, nos parece que nos encontramos frente a una causal eximente de responsabilidad, tanto del titular del proyecto o actividad, cuanto de la Autoridad admi-

${ }^{67}$ A juicio de Corral, "dudas podría plantear la posible inaplicabilidad de la responsabilidad compartida o solidaria de los Arts. 2316, inc. 2o, y 2317”. CORRAL, Hernán, Daño Ambiental y Responsabilidad Civil, en Revista Chilena de Derecho 26 (1996), pp. 151 - 152. Es decir, para dicho autor no es claro si la regla es aplicable $\mathrm{o}$ inaplicable.

${ }^{68}$ Barros, Enrique, cit. (n. 48), p. 422.

69 Sobre el punto, BArros, Enrique, cit. (n. 48), p. 423. 
nistrativa que lo autorizó ${ }^{70}$, sin perjuicio que ésta última igualmente deba llevar a cabo la reparación, ya no por haber sido condenada a ello, sino en cumplimiento del mandato constitucional que le impone el artículo $19 \mathrm{~N}^{\circ} 8$ de la CPR.

En efecto, sin perjuicio de los mandatos que imponen los principios de Derecho ambiental, especialmente los principios preventivo, precautorio y quien contamina paga ${ }^{71}$, nos parece que imputar responsabilidad a un sujeto en aquellas situaciones en que resultaba imposible prever el daño, implicaría generar una situación de incertidumbre jurídica contraria a derecho que atentaría contra otro de los principios que informan el Derecho ambiental, esto es, el del desarrollo sustentable.

De hecho, el propio SEIA reconoce la posibilidad de que ocurran hipótesis en que durante la ejecución del proyecto las variables evaluadas y contempladas en el plan de seguimiento hayan cambiado sustantivamente en relación a lo proyectado y, para tal evento, establece un procedimiento para adoptar las medidas necesarias para corregir dichas situaciones ${ }^{72}$.

Bajo este contexto, nos parece que la determinación de cuándo un daño ambiental era o no previsible, es una cuestión que deberá ser resuelta casuísticamente por los sentenciadores, quienes deberán considerar criterios tales como: $i$ ) la calidad y cantidad de información proporcionada en la evaluación ambiental; ii) las exigencias impuestas por la Administración y el cumplimiento de éstas por parte del titular durante la Evaluación Ambiental; iii) el nivel de análisis efectuado por la Administración de los antecedentes proporcionados por el titular; iv) la justificación y motivación de la decisión de calificación ambiental favorable del proyecto, expresada en la RCA respectiva; $v$ ) la consideración efectuada, por parte de la Autoridad evaluadora, de los informes técnicos de los órganos sectoriales expertos consultados; vi) los conocimientos de la técnica en un determinado momento ${ }^{73}$.

${ }^{70}$ En un sentido similar Delgado, Verónica, cit. (n. 13), p. 70.

${ }^{71}$ Femenías, Jorge, cit. (n. 4), pp.114-222.

${ }^{72}$ Cfr. el inciso $1^{\circ}$ del artículo 25 quinquies de la LBGMA. En el Derecho español se regula expresamente una hipótesis de exclusión de responsabilidad de la Administración similar en el artículo 141.1 de la LRJPAC. Para JORDANO, la limitación se encuentra más allá de lo constitucionalmente permitido. JORDANO, Jesús, La reforma del artículo 141, apartado 1, de la Ley 30/1992, de 26 de noviembre, o el inicio de la demolición del sistema de responsabilidad objetiva de las Administraciones públicas, en Revista de Administración Pública 149 (1999), pp. 324 y 333.

${ }^{73}$ Que, en España, por ejemplo, constituye una causal de exculpación a la luz de lo dispuesto en el artículo 141.1 de la Ley 30/1992. Leyes Administrativas, 20a edición, Madrid, Enero 2015, versión electrónica (proview) proveída por Thomson-Reuters. Laguna de Paz, José Carlos, La autorización, cit. (n. 20), p. 317. Para 
En síntesis, y resumiendo en una línea los asertos expuestos anteriormente, la imprevisibilidad e inevitabilidad del daño juegan como factores eximentes de responsabilidad, y sólo podría cuestionarse dicha condición en aquellas hipótesis de daños ambientales irreversibles ${ }^{74}$.

\section{DAÑOS OCASIONADOS POR ACTIVIDADES O PROYECTOS QUE NO SE ENCUENTRAN OBLIGADOS A INGRESAR AL SEIA}

Creemos que respecto de ellos no existe ninguna consideración especial -por tratarse de actividades económicas o desarrollos empresariales- y se aplican las reglas generales de responsabilidad por daño ambiental contempladas en la LBGMA y, en tal sentido, en el evento que ocasionen un daño ecológico puro se aplicará el régimen ordinario de responsabilidad consagrado en dicho cuerpo normativo, salvo, desde luego, que exista una norma especial que regule la reparación de los daños ambientales específicos que hubieran ocasionado (artículo 51 inciso $2^{\circ}$ ).

\section{CONCLUSIONES}

Para estudiar los factores subjetivos de imputación de los daños ambientales ocasionados en el marco de las actividades sometidas al Sistema de Evaluación de Impacto Ambiental es necesario, previamente, distinguir diversas hipótesis.

Así, tratándose de daños ambientales ocasionados por actividades que encontrándose obligadas a ser ingresadas al SEIA no lo hicieron, respecto de los efectos de la responsabilidad por daño ambiental, la única consecuencia jurídica que dicho incumplimiento presenta se verifica en que se configura la situación prevista en el inciso $1^{\circ}$ del artículo 52 de la LBGMA, dado que estaríamos ante la infracción de una norma de protección ambiental establecida en la propia LBGMA (el artículo 8 en concreto).

Para el caso de los daños ambientales ocasionados por actividades que encontrándose obligadas a ingresar al SEIA sí lo hicieron, para analizar como operarán los factores subjetivos de imputación de la responsabilidad por daño ambiental se deberá distinguir si se trata de daños autorizados en la evaluación; no autorizados en ella; o, finalmente, no considerados en la misma. Tratándose de este último caso, habrá que diferenciar nuevamente según se trate de daños previsibles o imprevisibles.

el autor, en todo caso, el denominado plus de responsabilidad "habría de venir establecido normativamente".

${ }^{74}$ RudA, Albert, cit. (n. 28), p. 415. 
Las consecuencias jurídicas de mayor trascendencia que se producirán en cada uno de los casos anteriores, dice relación con la posibilidad de aplicar la presunción de responsabilidad contenida en el inciso $2^{\circ}$ del artículo 52 de las LGBMA; así como la posibilidad de hacer responsable de la reparación de los daños al Estado.

En sintonía con lo expuesto precedentemente, la interpretación de las normas de la LBGMA a la luz del principios del Derecho ambiental, permite concluir que la Autoridad pública es responsable, solidariamente con el causante del daño, en aquellas hipótesis en que este es un tercero que obra mediante una autorización administrativa, particularmente, cuando estemos frentes a hipótesis de daños ambientales que no fueron previstos pero que sí eran previsibles (responsabilidad por la actuación del tercero autorizado).

Dicha responsabilidad deberá perseguirse contra la Administración a través del régimen establecido en la LBGMA y no sobre la base del estatuto propio que rige la responsabilidad patrimonial del Estado, precisamente por no tratarse de una hipótesis de responsabilidad patrimonial y por aplicación del principio de especialidad.

\section{BibLIOGRAFíA}

Astorga, Eduardo, Derecho ambiental chileno. Parte General (3a edición, Santiago, Abeledo Perrot - Thomson Reuters, 2012).

BANFI DEL Río, Cristián, De la responsabilidad civil como instrumento de protección ambiental, en Revista Chilena de Derecho Privado Fernando Fueyo Laneri 2 (2004).

BARros, Enrique, Tratado de responsabilidad Extracontractual (Santiago, Editorial Jurídica de Chile, 2007).

BERMúDEZ, Jorge, Derecho administrativo general ( $3^{\text {a }}$ edición, Santiago, LegalPublishing - Thomson Reuters, 2014).

BermúdeZ, Jorge, Fundamentos de Derecho Ambiental (2a edición, Valparaíso, Ediciones Universitarias Universidad Católica de Valparaíso, 2014).

BERMúdEZ, Jorge, La responsabilidad extracontractual de la administración del Estado por falta de servicio y por el daño ambiental, en Revista de Derecho de la Universidad Católica de Valparaíso XXIII, (2002).

Bermúdez, Jorge, Fundamentos de Derecho Ambiental, (2a Edición, Valparaíso, Ediciones Universitarias de Valparaíso, 2014.

Betancor, Andrés, Derecho Ambiental (Madrid, La Ley, 2014).

Conde, Jesús, El deber jurídico de restauración ambiental, (Granada, Editorial Comares, 2004).

Cordero, Encarnación, Derecho de daños y medio ambiente, en OrTega Álvarez, Luis (director), Lecciones de Derecho del Medio Ambiente, (4a edición, Valladolid, Lex Nova, 2005).

Corral, Hernán, Daño Ambiental y Responsabilidad Civil, en Revista Chilena de Derecho 26, (1996). 
Corral, Hernán, El sistema de impacto ambiental y la responsabilidad civil por daño al medio ambiente, en Revista de Derecho Administrativo Económico 1, (1999) 1.

Delgado, Verónica, La responsabilidad civil extracontractual por el daño ambiental causado en la construcción u operación de las carreteras, en Revista de Derecho Universidad Austral de Chile 1, (2012), 25.

Entrena, Rafael, Responsabilidad e inactividad de la Administración, en Martínez López-Muñiz, J. Luis y Calonge Velázquez, Antonio (coordinadores), La responsabilidad patrimonial de las Administraciones públicas. III Coloquio HispanoLuso de Derecho Administrativo. Valladolid, 16-18 de octubre de 1997, (Madrid, Marcial Pons, 1999).

FIAMma, Gustavo, La acción constitucional de responsabilidad y la responsabilidad por falta de servicio, en Revista Chilena de Derecho 16, (1989), 2.

GALERA, Susana, La responsabilidad de las administraciones públicas en la prevención de daños ambientales (Madrid, Ediciones Montecorvo, 2001).

García Enterría y Fernández, Tomás-Ramón, Curso de Derecho Administrativo (15a edición, Navarra, Civitas - Thomson Reuters, 2011), I.

GARRIDO, Fernando, Los limites de la responsabilidad patrimonial: una propuesta de reforma legislativa, en Revista Española de Derecho Administrativo 94, (1997).

Gómez, Marcos, La inactividad de la administración (4ª edición, Navarra, Aranzadi Thomson Reuters, 2011).

Gomis, Lucia, Responsabilidad por Daños al Medio Ambiente (Navarra, Aranzadi, 1998), p. 258.

Hunter, Iván, La culpa con la ley en la responsabilidad civil ambiental, en Revista de Derecho (Valdivia), [visible en internet: http://mingaonline.uach.cl/scielo.php?p $\mathrm{id}=$ S071809502005000200001\&script=sci_arttext.]

JANA, Andrés, et al., La responsabilidad Civil en el Proyecto de Bases del Medio Ambiente, en Revista Derecho y Humanidades, Universidad de Chile 1, (1992), 2.

Jiménez-Blanco Carrillo de Albornoz, Antonio, Responsabilidad Administrativa por culpa in vigilando o in commitendo" en VV.AA, Gobierno y Administración en la Constitución, (Madrid, Instituto de Estudios Fiscales, 1988).

JordANO, Jesús, Administración y responsabilidad por daños al medio ambiente: La construcción del régimen jurídico de los daños ambientales, en RuIz-Rico RuIz, Gerardo (director), La protección jurisdiccional del medio ambiente, (Madrid, Consejo General del Poder Judicial. Cuadernos de Derecho Judicial, 2001).

JORDANO, Jesús, La reforma del artículo 141, apartado 1, de la Ley 30/1992, de 26 de noviembre, o el inicio de la demolición del sistema de responsabilidad objetiva de las Administraciones públicas, en Revista de Administración Pública 149, (1999).

JoRDANO, Jesús, La responsabilidad de la Administración con ocasión de los daños al medio ambiente, en Revista de Derecho Urbanistico 119, (1990).

LaCruZ, José Luis, Elementos de Derecho Civil, vol. II (Madrid, Dykinson, 1999).

Laguna de PAZ, José Carlos, La autorización administrativa (Navarra, Thomson Civitas, 2006).

Laguna de Paz, José Carlos, Responsabilidad de la Administración por daños ambientales, en Noticias de las Unión Europea 305, (2010).

Laguna de PaZ, José Carlos, Responsabilidad de la Administración por daños causados por el sujeto autorizado, en Revista de Administración Pública 155, (2001).

Martín, Luis, Medio Ambiente y responsabilidad de la Administración en Revista Española de Derecho Administrativo 11, (1988). 
Moreno, Eulalia María, La protección jurídico-privada del medio ambiente responsabilidad por su deterioro, (Granda, Tesis para optar al Grado de Doctor en Derecho, [inédita], Universidad de Granada, 1990).

Pantaleón, Fernando, Los anteojos del civilista: hacía una revisión del régimen de responsabilidad patrimonial de las Administraciones públicas, en Documentación Administrativa 237-238, (1994).

PANTALEÓn, Fernando, Responsabilidad patrimonial de las Administraciones públicas: sobre la jurisdicción competente, en MARTín ReBOllo, Luis (director), Responsabilidad patrimonial de las Administraciones públicas. Cuadernos de Derecho Judicial, (Madrid, Consejo General del Poder Judicial, 1996).

PARADA, Ramón, Régimen Jurídico de las Administraciones Públicas y del procedimiento administrativo común. Estudio, comentarios y texto de la Ley $30 / 92$ de 26 de noviembre, (Madrid, Editorial Marcial Pons, 1993).

Pierry, Pedro, Responsabilidad del Estado por Daño Ambiental, ahora, en Silva AbraNETTO, Ximena (directora), Cumplimiento de la Legislación Ambientaly Reparación de Daños al Medio Ambiente, (Santiago, Consejo de Defensa del Estado, s.d.).

Rebollo, Martín, Servicios públicos concedidos y responsabilidad de la Administración: imputación o responsabilidad por el hecho de otro. Comentarios a la STS de 9 de mayo de 1989, en Poder Judicial 20, (1990).

RUDA, Albert, El Daño Ecológico Puro. La Responsabilidad Civil por el deterioro al Medio Ambiente, con especial atención a la Ley 26/2007, de 23 de octubre, de Responsabilidad Medioambiental, (Navarra, Thomson Aranzadi, 2008).

SAnz, Iñigo, Criterios del Consejo de Europa y ordenamiento español: Algunos problemas, en Martínez López-Muñiz, Martínez López- y Calonge Velázquez, Antonio (coordinadores), La responsabilidad patrimonial de las Administraciones públicas. III Coloquio Hispano-Luso de Derecho Administrativo. Valladolid, 16-18 de octubre de 1997, (Madrid, Marcial Pons, 1999), pp. 59-76.

Silva, Beatriz Adriana, Evaluación Ambiental: Impacto y Daño. Un Análisis Jurídico Desde la Perspectiva Cientifica, (Tesis para optar al grado de Doctor en Derecho, [inédita], Universidad de Alicante, Alicante, 2012).

Soto KLoss, Eduardo, Responsabilidad Administrativa Municipal, en Revista de Derecho y Jurisprudencia y Gaceta de los Tribunales 78, (1981), $1^{\text {a }}$ parte.

VÁzQuez de Prada, Valentín, Medio Ambiente y costes de contaminación, en Documentación Administrativa 178, (1978). 